\title{
CONSTRUÇÃO COLABORATIVA DE SABERES E PRÁTICAS SOBRE A AFETIVIDADE NA CRECHE
}

\author{
Viviane Aparecida Ferreira Favareto Cacheffo \\ Escola Municipal de Pirapozinho, Pirapozinho, SP. E-mail: vivianecacheffo@gmail.com. Agência de fomento: Capes
}

\begin{abstract}
RESUMO
Esse estudo contempla os dados obtidos na realização de um curso de formação continuada em serviço, com base nos pressupostos teóricos wallonianos, que buscou construir de modo colaborativo, com as professoras de creche, saberes e práticas para subsidiar o trabalho com a afetividade do bebê e da criança pequena. Para tanto, optou-se pela metodologia qualitativa, na modalidade pesquisa-ação-colaborativa, devido a suas potencialidades em relação à produção de conhecimento e de formação. Dessa forma, certificou-se a tese, de que os estudos da Psicologia podem contribuir para a Formação de Professores, uma vez que se configura como uma área do conhecimento que promove, para além do conhecimento teórico do desenvolvimento humano, a possibilidade de reflexão das práticas adotadas e realizadas. Da mesma maneira que a formação continuada precisa ser assumida como processo promotor da profissionalidade docente e, portanto, deve estruturar-se em função das necessidades formativas dos envolvidos no processo educativo.
\end{abstract}

Palavras-Chave: Afetividade. Henri Wallon. Formação de Professores. Educação Infantil. PesquisaAção-Colaborativa.

\section{COLLABORATIVE CONSTRUCTION OF KNOWLEDGE AND PRACTICES ON CRECHE AFETIVITY}

\begin{abstract}
This study contemplates the data obtained in the realization of a continuing education course in service, based on the theoretical Wallonian assumptions, which sought to construct in a collaborative way, with the nursery teachers, knowledge and practices to subsidize the work with the affectivity of the Baby and toddler. For that, we chose the qualitative methodology, in the research-action-collaborative modality, due to its potentialities in relation to the production of knowledge and training. Thus, it was certified the thesis, that the studies of Psychology can contribute to the Teacher Training, since it is configured as an area of knowledge that promotes beyond the theoretical knowledge of human development, the possibility of reflection on the practices adopted and performed. In the same way that continuing education must be assumed as a process that promotes teacher professionalism and, therefore, must be structured according to the training needs of those involved in the educational process.

Keywords: Affectivity. Henri Wallon. Teacher training. Child education. Research-ActionCollaborative.
\end{abstract}




\section{INTRODUÇÃO}

O presente artigo apresenta brevemente a tese: "Afetividade na creche: construção colaborativa de saberes e práticas docentes a partir da teoria walloniana", vinculada à linha de pesquisa Processos formativos, Infância e Juventude, do Programa de Pós-Graduação em Educação Doutorado ${ }^{1}$, da Faculdade de Ciências e Tecnologia - FCT/UNESP, que abordou a afetividade na formação de professores de Educação Infantil - creche.

A afetividade na perspectiva walloniana considera que o ser humano, desde o nascimento, afeta e é afetado, tanto positivamente quanto negativamente, imprimindo tonalidades agradáveis e desagradáveis às situações por ele vivenciadas. Para Wallon (1995, p. 128) “[...] a afetividade favorece a precocidade nas manifestações psíquicas da criança, encontrando-se ligada às suas necessidades e automatismos elementares, imediatamente consecutivos ao nascimento".

A afetividade é compreendida pela teoria walloniana, como uma das dimensões que, concomitantemente às demais (motora, cognitiva e pessoa), permitem a formação do indivíduo integral $^{2}$; entretanto, para fins de detalhamento e ampliação dos conhecimentos, tratarei apenas da dimensão afetiva na formação de professores.

Tendo por hipótese que a afetividade é uma lacuna na formação inicial de professores, busquei contribuir com a formação continuada de professores, de forma a lançar-me como formadora de professores e vivenciar a amplitude desse processo, assim como suas contribuições e limites.

Dessa maneira, com o intuito de identificar, na teoria do desenvolvimento de Henri Wallon, saberes teóricos e práticos em relação à afetividade e à formação e função do professor de Educação Infantil - creche, delimitei, por objetivo, realizar um curso de formação continuada ${ }^{3}$ em serviço, com base nos pressupostos teóricos wallonianos, a fim de identificar de modo colaborativo, com as professoras de creche do município de Pirapozinho/SP, saberes e práticas para subsidiar o trabalho com a afetividade do bebê e da criança pequena (04 meses a 3 anos e 11 meses).

\section{METODOLOGIA}

A pesquisa-ação-colaborativa, como prática social foi definida, devido às suas potencialidades quanto à produção de conhecimento e formação, proporciona a interação entre as professoras de creche, a pesquisadora e os objetos do conhecimento, com o intuito de compreender e aprimorar os conhecimentos teóricos e práticos referentes ao desenvolvimento afetivo infantil e, dessa forma, estabelecer a autoformação de todos os envolvidos na pesquisa (DESGAGNÉ, 2007).

Ibiapina (2008), a partir da análise dos postulados de Carr e Kemmis (1998), elaborou um quadro das modalidades de pesquisa-ação: pesquisa-ação técnica, prática e emancipatória - na qual se encontra o aspecto colaborativo. Nessa perspectiva, as decisões são coletivas e permeadas por negociações e se fundam em um movimento dialético entre a teoria e a prática, problematização das práticas educativas, por meio da reflexividade ${ }^{4}$, e predominância da coprodução e colaboração, promovendo a formação contínua.

A pesquisa colaborativa possibilita a interação entre pares que possuem diferentes níveis de saberes e competências, facilitando as trocas na realização da investigação, promovendo uma

\footnotetext{
${ }^{1}$ Pesquisa orientada pela Professora Doutora Gilza Maria Zauhy Garms

${ }^{2}$ Wallon (1979) nos apresenta que o ser humano integral é constituído pelas seguintes dimensões: afetiva, motora, cognitiva e pessoa.

${ }^{3}$ Compreende-se formação continuada "[...] como um processo dinâmico por meio do qual ao longo do tempo, um profissional vai adequando sua formação às exigências de sua atividade profissional." (ALARCÃO, 1998, p. 100).

4 "A reflexividade é a capacidade de voltar sobre si mesmo, sobre as construções sociais, sobre as intenções, representações e estratégias de intervenção. Supõe a possibilidade, ou melhor, a inevitabilidade de utilizar o conhecimento, à medida que vai sendo produzido, para enriquecer e modificar não somente a realidade e suas representações, mas também a próprias intenções e o próprio processo de conhecer." (PÉREZ GÓMEZ, 1998, p. 29).
} 
ação formativa que implementa o desenvolvimento pessoal e profissional dos envolvidos nesse processo.

Assim, contribui para formar e formar-se, apresentando as contribuições teóricas e práticas da teoria walloniana e promovendo reflexões orais e escritas das professoras inseridas no processo formativo.

A proposta de formação continuada em serviço ${ }^{5}$ foi estruturada em três temáticas a partir da análise das respostas obtidas pela aplicação de questionários: Cuidar e educar; Profissionalidade; e Desenvolvimento afetivo infantil: nos documentos, na teoria e nas práticas, fundamentada em uma epistemologia dialética; base do desenvolvimento da teoria de Henri Wallon, e calcada nas reflexões das práticas (SCHÖN, 1983).

A formação continuada aconteceu quinzenalmente, durante os meses de agosto a dezembro de 2015, em 8 encontros com duração média de 120 minutos, com 14 participantes 12 professoras e 02 vice-diretoras, pertencente a duas instituições municipais de Educação Infantil - creche, do município de Pirapozinho/SP.

Os instrumentos metodológicos - grupo de discussão, narrativas orais e escritas e diários de aula, permitiram constatar quais saberes e práticas as professoras de creche mobilizam, para lidar com as expressões emocionais que compõem a dimensão afetiva; assim como, refletir e dialogar sobre a função da professora de creche, com ênfase no desenvolvimento dos saberes sobre a afetividade e suas manifestações no desenvolvimento infantil, a partir dos subsídios teóricos de Henri Wallon.

A escolha de dispositivos metodológicos inerentes à metodologia qualitativa, na modalidade de investigação-ação-colaborativa, intencionou tornar públicos os sentidos, significados e interpretações que os professores produzem, quando dialogam, escrevem e refletem sobre suas práticas educativas (SUÁREZ, 2010).

\section{RESULTADOS}

A análise dos dados recolhidos permitiu a construção de quatro categorias: "A constituição da professora de creche: o embate cuidar e educar"; "Profissionalidade"; "As emoções nas práticas educativas"; e "Possibilidades e limites da formação continuada em serviço".

\section{DISCUSSÃO}

Nas categorias "A constituição da professora de creche: o embate cuidar e educar" ${ }^{\prime}$ e "Profissionalidade"; as profissionais colaboradoras da investigação apresentaram nas narrativas do grupo de discussão e dos diários, relatos que demonstram que a profissionalidade das professoras de creche ainda está em construção e que as características da maternagem ainda são evocadas para caracterizar o trabalho desenvolvido.

Então, é um papel, faz um papel de mãe, e outras horas também, você está ali no cuidado, você está no papel de mãe, na hora do carinho mesmo, te chama de mãe o tempo todo. Se você se colocar no lugar da mãe daquela criança, você já age diferente. Você percebe aquele olhar para você, e pensa: - Se fosse o meu filho? (Relato oral da professora Rosa - grupo de discussão).

Eu não sou mãe, eu sou professora, eu acho que a função da mãe é completamente diferente da professora. Não podemos confundir. Cada um

\footnotetext{
${ }^{5}$ Pesquisa aprovada pelo Comitê de Ética: CAAE: 56220716.1.0000.5402

${ }^{6}$ Função dos professores da Educação Infantil - DCNEI/1999; DCNEI/2009. 
tem um papel na educação da criança. (Relato oral da professora Zenaide grupo de discussão).

Eu, como professora da Educação Infantil, educo e cuido visando à formação integral do aluno, que só é possivel por meio afetividade estabelecida entre ele e as pessoas com as quais convivem. Esta questão, apesar de ser algo evidente aos profissionais da referida área, ainda carece ser discutida e estudada, devido haver alguns profissionais que acreditam que o professor só tem que trabalhar a parte pedagógica, enquanto o cuidar é para "as tias" e que o afeto tem que ficar em segundo plano. (Narrativa da professora Dulcineia - diário de aula).

No que diz respeito " A constituição da professora de creche: as emoções nas práticas educativas", constatou-se que a participação na formação continuada modificou as posturas e compreensão sobre a afetividade.

O curso acrescentou positivamente no meu trabalho com as crianças, as leituras textuais e a troca de experiências com as outras profissionais me levaram a algumas práticas que obtiveram resultados inclusive relatados em algumas experiências no próprio diário. Veio de encontro com as necessidades encontradas diariamente e a troca de experiência foi muito boa, pois são dificuldades muito parecidas umas com as outras ainda que sejam em creches diferentes. (Professora Nezilda - diario de aula).

O curso contribuiu muito com a minha prática, pois passei a avaliar as minhas crianças com um olhar especial sobre as emoções. Por meio dos textos pude avaliar a minha prática e ter um olhar mais profissional sobre como as emoções influenciam tudo a nossa volta. Confesso que nunca havia pensado na emoção sobre o foco da afetividade e pude averiguar que somos constantemente influenciados pelas emoções. O curso valorizou ainda mais a minha prática e me levou a pensar e ter reações diferentes sobre o que acontece a minha volta e principalmente profissionalmente. (Professora Zenaide - diario de aula).

As emoções configuram-se como a linguagem não-verbal da criança a qual implementa sua relação com o meio humano e físico, com o intuito de satisfazer suas necessidades, primeiramente biológicas e posteriormente sociais. Para a teoria walloniana, o meio humano é o maior potencializador do desenvolvimento psicológico infantil, e a afetividade, o conjunto funcional com maior preponderância no início da vida do bebê e da criança pequena.

Wallon (1995) destaca que os três primeiros anos de vida da criança formam o cenário propício para identificar a relevância da emoção, no estabelecimento de interações e seus impactos na vida orgânica e psíquica infantil. Conforme o autor, desde o nascimento, o bebê interage com o meio externo, com o auxílio da motricidade e da afetividade, todavia, para isso, precisa que um adulto signifique suas expressões emocionais.

Quando a professora conhece as especificidades de cada criança, ela consegue identificar o que revelam suas manifestações emocionais, de tal modo que busca estratégias para eliminá-las, utilizando os recursos possibilitados pela cognição. Quando colocados aos recursos da inteligência, os estados emocionais tendem a desaparecer (WALLON, 1971). 
Para Wallon (1979), os professores da escola maternal ${ }^{7}$ têm por função o estabelecimento de uma disciplina que permita à criança ser feliz, e interações "[...] quase de natureza maternal." (WALLON, 1979, p. 208).

O termo "quase" sublinha a especificidade da professora de creche, pois, embora a criança necessite dos cuidados ligados ao desenvolvimento físico - alimentação, trocas, sono e contato corporal, que inicialmente são desenvolvidos pela mãe ou pelo adulto mais próximo da criança, quando realizados pelas professoras, ampliam as formas de significação da criança quanto ao toque recebido, ao olhar direcionado, aos horários estabelecidos, à espera para o seu atendimento e ao envolvimento emocional diferenciado. Os cuidados são parecidos com os exercidos pela mãe, mas com uma diferença substancial: a intencionalidade. Conforme Wallon (1995), a melhor forma de conhecer a criança é pela observação. A professora precisa refinar seu olhar, para ler as expressões emocionais infantis, seus estados de bem-estar e mal-estar, pois, muito antes da palavra, é pelos recursos da afetividade que se instaura a comunicação entre criança e adultos.

Em relação à categoria - "Possibilidades e limites da formação continuada em serviço", pode-se citar a dificuldade das professoras em registrar sistematicamente nos diários, e o receio de expressar seus entendimentos diante as duas vice-diretoras que também participaram da formação.

\section{CONCLUSÃO}

Para Nóvoa (1995), as propostas de formação devem considerar as situações e contextos vivenciados pelos professores, visando a oportunizar diálogos e ações concernentes à realidade singular presenciada.

Nóvoa (1992) também afirma que as investigações de professores deve considerar os diversos aspectos da história individual e pessoal de cada professora. A formação de professores precisa valorizar os saberes mobilizados pelos profissionais, ou seja, "[...] é preciso investir positivamente nos saberes de que o professor é portador, trabalhando-os de um ponto de vista teórico e conceptual." (NÓVOA, 1992, p. 27).

A teoria e a prática devem estar articuladas na formação inicial e continuada das professoras de creche. A formação precisa ser significativa, de modo a não priorizar um polo em detrimento ao outro, isto é, a teoria se sobrepor a prática, ou a cognição suplantar a afetividade. A formação de professores precisa ser pensada a partir da integralidade do profissional que será o mediador do processo educativo de crianças integrais, cujo desenvolvimento é composto, conforme a teoria walloniana, pelas dimensões afetiva, cognitiva e motora; reitere-se que, nesta pesquisa, por critérios de detalhamento, apresentou-se a afetiva.

Nesse sentido, a compreensão das manifestações da afetividade, suas significações, seus impactos nas interações entre as crianças, adultos e objetos do conhecimento, assim como suas expressões para garantia da autonomia e formação da personalidade, precisam contemplar os saberes das professoras de creche. As trocas afetivas realizadas cotidianamente, no ambiente educacional, necessitam ser significadas. As práticas afetivas carecem de aporte teórico.

A teoria walloniana é um subsidio para as práticas das professoras. Nos encontros de aprofundamento e análise das práticas, foi possível identificar as manifestações afetivas propostas por Wallon nos relatos orais e escritos compartilhados pelas professoras, assim como as características das emoções, em destaque - o contágio, que permitia que as necessidades infantis fossem atendidas, e o estabelecimento do circuito perverso em situações nas quais as professoras deixavam-se agir pela emoção. Também constatou-se que a dimensão motora e a representação mental são estratégias adequadas para promover a latência dos estados emocionais.

\footnotetext{
${ }^{7}$ Etapa educacional francesa que atende crianças de 3 a 5 anos.
} 
Outro contributo, a articulação entre a teoria e a prática na formação de professores, assim como da Pedagogia com a Psicologia corroborou para a afirmação da tese de que os estudos da Psicologia podem contribuir para a Formação de Professores, uma vez que se configura como uma área do conhecimento que promove para além do conhecimento teórico do desenvolvimento humano, a possibilidade de reflexão das práticas adotadas e realizadas.

Assim a produção de Henri Wallon a partir dos seus subsídios teóricos permite a construção de saberes pedagógicos e práticos sobre o desenvolvimento afetivo infantil, contribuindo para a constituição da profissionalidade das professoras de bebês e crianças pequenas.

\section{REFERÊNCIAS}

ALARCÃO, I. Formação continuada como instrumento de profissionalização docente. In: VEIGA, I. P. A. (Org.). Caminhos da profissionalização do magistério. Campinas: Papirus, 1998.

BRASIL. Ministério da Educação. Conselho Nacional de Educação. Câmara de Educação Básica. Parecer CEB n. 22/98. Resolução CEB n.1, 7 de abril de 1999. Diretrizes Curriculares Nacionais para a Educação Infantil. Brasília, DF: CNE/CEB, 1999.

. Ministério da Educação. Conselho Nacional de Educação. Câmara de Educação Básica. Parecer CNE/CEB no 20, de 11 de novembro de 2009. Revisão das Diretriz Curricular Nacional para Educação Infantil. Brasília, DF: MEC/SEB, 2009.

CARR, W.; KEMMIS, S. Teoria critica de la ensenanza. Barcelona: Martinez Roca, 1998.

DESGAGNÉ, S. Reflexões sobre o conceito de pesquisa colaborativa. Tradução livre: Adir Ferreira. Les Journèes du Cirade. Université du Québec à Montreal, oct. 1998.

. O conceito de pesquisa colaborativa: a ideia de uma aproximação entre pesquisadores universitários e professores práticos. Revista Educação em Questão, Natal, v. 29, n. 15, p. 7-35, maio/ago. 2007.

NÓVOA, A. Os professores e as histórias da sua vida. In: NÓVOA, A. (Org.). Vidas de Professores. Porto: Porto Editora, 1995. p. 11-30.

(Coord.). Os professores e a sua formação. 2. ed. Lisboa: Dom Quixote, 1992.

PÉREZ GÓMEZ, A. I. A função e formação do professor/a no ensino para a compreensão: diferentes perspectivas. In: SACRISTÁN, J. G.; PÉREZ GÓMEZ, A.I. Compreender e transformar o ensino. Porto Alegre, Artmed, 1998.

SCHON, D. Educating the reflective practitioner. San Francisco: Jossey-Bass, 1983.

SUÁREZ, D. H. La documentación narrativa de experiencias pedagógicas como estrategia de indagación-acción-formación de docentes. In: PASSEGGI, M. C.; SOUZA, E. C. (Org.). Memoria docente, investigación y formación. Buenos Aires: CLACSO y Facultad de Filosofía y Letras, UBA, 2010.

WALLON, H. As origens do caráter na criança. São Paulo: Difusão Europeia do Livro, 1971. 
Psicologia e educação da criança. Lisboa: Veiga, 1979.

. A evolução psicológica da criança. Lisboa: Edições 70, 1941/1995. 